\title{
EL GRUPO DE BARRANQUILLA
}

\author{
POR \\ JACQUES GILARD \\ Université de Toulouse-Le Mirail
}

A pesar de su vida desordenada, todo el grupo trataba de hacer algo perdurable a instancias del sabio catalán.

(Gabriel García Márquez, Cien años de soledad)

Del grupo de Barranquilla aparecen datos en las obras de García Márquez. Están los personajes de Alfonso, Alvaro y Germán, dependientes de la sastrería del pueblo en El coronel no tiene quien le escriba. Están los mismos, más el sabio catalán y Gabriel, en Cien años de soledad. Está la alusión a «los mamadores de gallo de La Cueva» en las primeras líneas del cuento «Los funerales de la Mamá Grande», y la alusión a Alvaro Cepeda Samudio en el cuento «La increíble y triste historia...». Así se puede sospechar la existencia de algunos amigos de García Márquez y también, con lo que aparece en Cien años de soledad, el fervor de sus debates sobre cuestiones literarias. Un estudio de ese grupo de amigos se justifica en la medida en que, además de suministrar datos sobre lo que con desafortunada fórmula algunos han llamado «prehistoria literaria» de García Márquez, permite conocer las excelentes obras de Alvaro Cepeda Samudio y José Félix Fuenmayor y, de manera ya algo marginal, la de Ramón Vinyes, «el sabio catalán».

\section{EL NÚCLEO: LOS PERIODISTAS}

La fe de bautismo del grupo de Barranquilla la estableció algo tardíamente uno de sus miembros, el periodista Germán Vargas, en una crónica 
escrita probablemente hacia fines de $1955^{1}$. Un año antes, otro periodista, bogotano éste, Próspero Morales Pradilla, había señalado en algunas páginas del principal suplemento literario del país, el de El Tiempo de Bogotá, la muy activa y muy peculiar vida intelectual y artística que existía en el gran puerto caribeño, pero sin concretarse realmente a lo que era ya el grupo propiamente dicho ${ }^{2}$. Este existía desde hacía unos años $-y$ seguiría existiendo hasta la década de los sesenta - sin que el país supiera de él ni, además, prestara atención a lo que se hacía en esa ciudad que todos solían considerar como «ciudad fenicia» o «ciudad de tenderos».

La crónica de Germán Vargas contribuía a fijar para el exterior los contornos borrosos del grupo, pero no representaba una toma de conciencia por parte de sus miembros. Estos sabían, desde antes de 1950, que constituían una entidad, sumamente informal, pero entidad de todas maneras, aunque estaban dispuestos a acoger gentes e ideas nuevas y se negaban a establecer una nómina cerrada o un ideario inmutable.

Germán Vargas afirmaba que el grupo se había ido formando espontáneamente en los años cuarenta alrededor de Ramón Vinyes - lo cual resulta del todo exacto ${ }^{3}$-, pero no menciona al escritor barranquillero José Félix Fuenmayor, que, en nuestra opinión, aunque se manifestó muy poco entonces, se hizo eco de los debates del grupo y tuvo un papel de orientador a través de la redacción y la publicación de un reducido número de cuentos ${ }^{4}$. Luego cita Germán Vargas los nombres de los miembros permanentes del grupo: además de él mismo, Alfonso Fuenmayor (hijo de José Félix), Alvaro Cepeda Samudio y Gabriel García Márquez. Este último, en realidad, sólo vivió en Barranquilla unos cuatro años (1950-53), con algunas interrupciones, pero por la forma en que, ya en 1955, había ilustrado los conceptos del grupo, se le podía considerar como uno de sus miembros permanentes. Cita además Germán Vargas bastantes nombres más, entre los que cabe destacar los de Bernardo Restrepo Maya y Ale-

${ }^{1}$ Germán Vargas, «El grupo de Barranquilla». Tomado de Suplemento del Caribe (Barranquilla, núm. 12, 14 de octubre de 1973), p. 13. Esta edición se reproducía de Vanguardia Liberal (Bucaramanga, 22 de enero de 1956). Conocemos también un recorte sin fecha de El Colombiano, de Medellín, conservado en el archivo de Alvaro Cepeda Samudio. Según la introducción que figura en este recorte, Germán Vargas había escrito esta crónica para una revista bogotana, donde salió desfigurada.

2 Próspero Morales Padilla, «Barranquilla llega a las letras», El Tiempo (Bogotá, 28 de noviembre de $1954,2 .^{a}$ sección), p. 3.

${ }^{3}$ Cfr. Ramón Vinyes (recopilación, selección y prólogo por Jacques Gilard), Selección de textos (Bogotá: Instituto Colombiano de Cultura, 1982), pp. 626 y 400.

${ }^{4}$ Esos cuentos fueron recopilados tardíamente y publicados después de la muerte del autor. José Félix Fuenmayor, La muerte en la calle (Medellín: Ed. Papel Sobrante, 1967), p. 152. 
jandro Obregón. Existen pocas huellas de la actividad del primero - unas cuantas publicaciones en la prensa-, pero estuvo vinculado al grupo desde el principio (el regreso de Vinyes a Barranquilla, en 1940) y fue un eficiente organizador de manifestaciones artísticas. En cuanto a Obregón, quien perteneció al grupo antes y después de la estadía de García Márquez y nunca convivió con éste en Barranquilla, es uno de los nombres más destacados de la pintura colombiana contemporánea; después de 1955, en la época del bar «La Cueva» - un bar que García Márquez nunca frecuentó-, las artes plásticas representaron en el grupo, gracias a Obregón, lo que la literatura había sido alrededor de 1950.

El grupo, desordenada y variable constelación de amigos que hacían una «amable bohemia» (según expresión de Germán Vargas), había definido su personalidad en 1950, cuando, quince días después de regresar a Cataluña Ramón Vinyes, el sábado 29 de abril, apareció el primer número del semanario «literario-deportivo" Crónica, que era su órgano, o lo fue por unos meses, hasta diciembre de ese año, antes de entrar en decadencia y desaparecer en junio de $1951^{5}$. Era su director Alfonso Fuenmayor, y su jefe de redacción, García Márquez. Los que más colaboraron en el semanario, además de los dos citados, fueron Germán Vargas y Cepeda Samudio. Allí se empieza a ver qué bases tenía Germán Vargas, cinco años después, para afirmar que ellos cuatro habían sido los pilares del grupo.

Los cuatro eran periodistas - como lo habían sido Ramón Vinyes y José Félix Fuenmayor- y en esa calidad de profesionales de la cosa escrita aparece otro elemento que justifica la aseveración de Germán Vargas sobre el núcleo esencial del grupo. El caso es que son precisamente sus escritos los que nos suministran las bases documentales útiles para conocer las opiniones y las ambiciones del grupo -mucho más que los escritos del «sabio catalán» y que los cuentos de José Félix Fuenmayor.

La profesión de los cuatro periodistas —o de los tres barranquilleros, si se tiene en cuenta el que García Márquez fue un advenedizo- da la clave de varios aspectos en las actividades y las características del grupo. Ellos eran hombres de comunicación y jóvenes que, por ser jóvenes, se adaptaban fácilmente a las exigencias de una época - los años cuarenta- que era de rápido desarrollo de los medios de comunicación. De allí se seguían la variedad de los temas sobre que escribían (muchas «cosas del día» y pocas cuestiones culturales), su dependencia con respecto al material de actualidad (aunque es probable que no se propusieron ser sistemáticos. no les fue posible serlo) y sobre todo su dependencia con respecto a las

${ }^{5}$ Cfr. Jacques Gilard, «Historia de Crónica», en Gaceta (Bogotá), núm. 35, 1981, pp. 24-32; núm. 36, 1982, pp. 21-32. 
normas según las cuales se desarrollaba la vida intelectual colombiana (sólo podían aceptarlas o rechazarlas). Es posible sacar en claro unos cuantos principios, pero es siempre a través de una reacción frente a unos hechos concretos y una realidad nacional específica. Es difícil destacar el sentido de una aseveración sin tener que referirse antes a la circunstancia que la generó. Hablar del ideario del grupo, inevitablemente, es describir el estado de cosas contra que reaccionaba y, con frecuencia, acudir a lo anecdótico. Ese ideario se ve, además, disperso en una cantidad de notas breves y generalmente reacias a una síntesis rigurosa.

La connotación geográfica impone una evocación del posible ingrediente localista o regionalista en los planteamientos del grupo de Barranquilla. Es cierto que un sutil ingrediente de reivindicación regional puede haber dejado huellas en los conceptos y los escritos de sus miembros. Su región, la Costa Atlántica, puede decirse que, más que formar parte de Colombia, le pertenecía. La imagen del país se había forjado esencialmente en la parte andina, por evidentes razones de geografía, de tradicional dificultad de comunicar y de organización administrativa. La nacionalidad -la idea que de ella se hacían los altos círculos intelectuales y políticos- no coincidía con los límites geográficos del país. Fuera de las viejas ciudades coloniales (Santa Marta y Cartagena), la Costa y su humanidad mulata o se desconocían o inquietaban, como una presencia indeseable de las exóticas Antillas y del Africa oscura. Barranquilla, aldea en el siglo xix y urbe moderna en 1950, era una emanación de esa Costa «profunda» y no encajaba en la noción de ciudad colombiana: era una población opulenta y activa, pero cosmopolita y sin tradiciones. El lugar común de «ciudad de tenderos» presuponía la ausencia de una actividad cultural.

La realidad era distinta, pero la condición de puerto, y de puerto joven, hacía muy difícil que la vida cultural de Barranquilla y sus particularidades fueran percibidas desde las ciudades de raigambre colonial. Había una apertura hacia afuera que generaba una actitud sui generis y, desde hacía tiempo, actividades vinculadas a la azarosa vida de una prensa local escasamente proyectada hacia el interior del país. Los miembros del grupo sabían de la existencia de la revista Voces ${ }^{5}$, animada de 1917 a 1920 por el «sabio catalán», de publicaciones y de libros de elevado nivel que se desconocían en el resto del país. Y la curiosidad por lo foráneo, que heredaban de la tradición local generada por la geografía, hacía que ellos estuvieran convencidos de que las posturas de valor universal pertenecían más bien a la Costa, mientras que las posturas provin-

${ }^{6}$ Cfr. Germán Vargas, recopilador y prologuista, Voces. 1917-1920. Selección de textos (Bogotá: Instituto Colombiano de Cultura, 1977), p. 432. 
cianas predominaban en el interior y especialmente en Bogotá. Por otra parte, la mentalidad de los barranquilleros se nutría del orgullo de ser una ciudad de progreso, nacida del progreso, la que primero había tenido teléfono, luz eléctrica, acueducto, compañía de aviación, emisoras de radio, y estaba más en contacto con el mundo; la sociedad del interior del país les parecía anacrónica en muchos aspectos.

En ese concepto de que el interior era provinciano y anacrónico, la vanidad local podía tener algún papel, pero, en realidad, tratándose del grupo de Barranquilla, ese papel debía ser nulo o sumamente marginal. Sus planteamientos no tenían que ver con criterios espaciales, sino con una exigencia de seriedad intelectual, de rigor crítico y de calidad estética. Denunciaban o se burlaban de lo que les parecía mal hecho, pero nunca condenaron un libro por ser obra de un hombre del interior (un «cachaco») y se empeñaron siempre en ver el mérito propio de todo lo que leían, viniera de donde viniera. León de Greiff, Eduardo Zalamea Borda, Hernando Téllez, Alvaro Mutis, para citar solamente algunos nombres de escritores interioranos, tuvieron en los miembros del grupo lectores atentos.

Los sarcasmos fueron contra lo provinciano y anacrónico, pero, desde luego, subrayando irónicamente la condición de esos provincianos - los barranquilleros-, irritados por las ínfulas y las intrigas de los intelectuales de la capital. Escribía, por ejemplo, Alvaro Cepeda Samudio:

Se queja José Ignacio Libreros en su «Noticiario Cultural» de $E l$ Tiempo de que en Correo, revista de la Unión Panamericana, se haga caso omiso de nuestra actividad literaria y artística. Cabe preguntarle a JIL a cuál actividad se refiere, porque nosotros, los de «provincia», no tenemos noticia alguna de los movimientos literarios y artísticos de los guardadores de nuestras tradiciones culturales ${ }^{7}$.

\section{Y Germán Vargas:}

No había visto hasta ahora que ningún escritor abocara el asunto de la pobreza de los suplementos dominicales de los diarios capitalinos desde uno de esos diarios, como lo ha hecho Wills Ricaurte. Es la suya una actitud meritoria, que traduce el pensar de muchas gentes de la

7 Alvaro Cepeda Samudio, 'En el margen de la ruta', «Nuestra actividad literaria», en El Nacional (Barranquilla, hacia el 28 de enero de 1948). Por haberse perdido en parte las colecciones de ese diario, subsisten solamente recortes sin fechar de algunos artículos de Cepeda Samudio. Los fechamos a partir de los hechos aludidos o de los artículos de prensa que comentaban. Esas pérdidas afectan aproximadamente a la mitad de lo que Cepeda publicó en El Nacional. 
provincia, como graciosa y peyorativamente nos llaman los provincianos cuando pontifican desde la capital ${ }^{8}$.

Dos años después, escribiría García Márquez:

Hace algunos días (...) un inteligente amigo me advertía que mi posición con respecto a algunas congregaciones literarias de Bogotá era típicamente provinciana. Sin embargo, mi reconocida y muy provinciana modestia me alcanza, creo, hasta para afirmar que en este aspecto los verdaderamente universales son quienes piensan de acuerdo con este periodista sobre el exclusivismo parroquial de los portaestandartes capitalinos. El provincianismo literario en Colombia empieza a dos mil quinientos metros sobre el nivel del mar ${ }^{9}$.

La inquina local solamente suministraba una forma corrosiva de decir las cosas; lo esencial se situaba a otro nivel. Lo había expresado Alfonso Fuenmayor en una importante nota sobre el pintor Alejandro Obregón, quien, en una reciente exposición realizada en Bogotá, no había podido vender un solo cuadro:

Todavía pesa sobre (los círculos literarios y artísticos) una cantidad de prejuicios desde hace tiempo evaporados en otros centros, que tienen su postrer y enérgica vigencia en Bogotá ${ }^{10}$.

\section{EL IDEARIO DEL GRUPO}

La palabra «ideario» tal vez resulte bastante holgada para definir la serie de planteamientos del grupo, relativos a cuestiones ideológicas, culturales y estéticas, dado el papel de elementos muy circunstanciales en la expresión de esos planteamientos. Y el grupo hubiera rechazado la palabra con sorna. Puede verse la quintaesencia de esas posturas en una frase de la ya citada nota de Alfonso Fuenmayor sobre el pintor Obregón:

\footnotetext{
${ }^{8}$ Germán Vargas, «Nota intrascendente», en El Nacional (Barranquilla, 14 de agosto de 1948), p. 5.

'Gabriel García Márquez (Septimus), 'La Jirafa', «Otra vez Arturo Laguado», en El Heraldo (Barranquilla, 27 de abril de 1950). Cfr. Gabriel García Márquez (recopilación y prólogo por Jacques Gilard), Obra periodística, vol. 1: Textos costeños (Barcelona: Ed. Bruguera, 1981), p. 273.

${ }^{10}$ Alfonso Fuenmayor, 'Aire del día', "Obregón en Bellas Artes», en El Heraldo (Barranquilla, 7 de junio de 1948), p. 3.
} 
Obregón (...) realizará la revolución artística que desde hace tiempo está necesitando Colombia, si quiere, y éste debe ser un imperativo de nuestra cultura, ponerse no ya en un plano de avanzada, sino, apenas, a tono con la hora del mundo.

Más adelante iremos viendo qué implicaba esa especie de programa - de cuya realización no se encargaba el grupo, según se desprende de la frase aquí reproducida, así como del conjunto de su comportamiento-, pero está claro que sólo se trató de ilustraciones algo desordenadas de ese principio según el cual había que vivir en «la hora del mundo».

Conviene interrogarse un poco sobre la manera como el grupo se fue manifestando en la vida cultural colombiana, o tal vez sería mejor hablar de cómo trató de no manifestarse. Sus miembros, unánimes, pensaban que las reglas del juego estaban demasiado viciadas para que valiera la pena. participar en él bajo la aparente forma de una prédica más. De allí que se limitaran a una actividad periodística, circunscrita a la prensa local de Barranquilla.

Es llamativo el hecho de que no escribieran ensayos, un género que florecía en los suplementos de Bogotá y en las principales revistas literarias del país. Una revisión de esas publicaciones demuestra que varias generaciones de intelectuales colombianos se han desgastado en la práctica de ese género, que les quitó energía y tiempo, pudiendo haberlos invertido en actividades más creativas. Eran además una forma degenerada del ensayo, por falta de exigencia, textos pensados y escritos precipitadamente, con miras a un éxito superficial, de tipo más «social» que intelectual. De textos de esa naturaleza se llenaban las páginas del suplemento más prestigioso, el de El Tiempo de Bogotá. Además, muchas columnas dominicales, atendidas por periodistas cotizados o por escritores del interior, constituían un último avatar del género ensayístico. Allí se perpetuaban, generándose constantemente a sí mismos, rasgos de la vida intelectual colombiana que el grupo repudiaba, y por ello sus miembros nunca publicaron ensayos; no les interesaba explicar, sino informar y opinar.

También por esta vía se explica que su ideario se exprese ante todo en notas periodísticas, algunas de las cuales, sin embargo, podrían llegar a definirse como una categoría de ensayo muy propia del grupo y bastante innovadora: textos breves - o levemente más largos que una simple nota de comentario-, de planteamientos escuetos y conclusiones expeditivas, desprovistos de matices. Existen en ínfima cantidad y son solamente la sugerencia de algo que pudo ser: una modalidad periodística del ensayo crítico que habría sido un aporte notable si hubiera existido una compatibilidad mínima entre el grupo y la vida cultural del país. Algunas notas 
de Alfonso Fuenmayor se aproximan a ese tipo de ensayo, pero fueron Germán Vargas y Alvaro Cepeda Samudio quienes mejor lo ilustraron en muy contadas ocasiones. El primero, con "Fichas sin revisar» ${ }^{11}$ y «Sobre el cuento colombiano» ${ }^{12}$; el segundo, con una entrega de su columna «Brújula de la cultura» ${ }^{13} \mathrm{y}$ «El cuento y un cuentista» ${ }^{14}$, breves textos que, gracias a su densidad, constituyen ineludibles fuentes para el conocimiento de los juicios del grupo sobre la narrativa colombiana (el primero citado) y sobre el cuento (los otros tres). Años más tarde, en sus panfletos de 1959 y 1960, García Márquez retomó algo del tono y la manera de sus amigos al enjuiciar la líteratura nacional ${ }^{15}$.

Otro rasgo, vinculado indefectiblemente con el anterior, es la reticencia del grupo ante la posibilidad de publicar en Bogotá. Lo hicieron muy poco sus miembros. Se entiende que no les atraía la idea de colaborar en el suplemento de $E l$ Tiempo, la hoja poco menos que oficial donde reinaba plenamente el sistema que ellos repudiaban, pero tampoco lo hicieron en El Espectador, que seguía una línea bastante irreverente y podía haberles convenido como vector de su expresión. En los primeros años de existencia del grupo, el mismo Ramón Vinyes, quien gozaba de un prestigio notable, solamente se manifestó tres veces, con dos artículos en el suplemento de El Tiempo ${ }^{16}$ y uno en la Revista de América, que dirigia Germán Arciniegas ${ }^{17}$. En lo que ya era una época de plena existencia del grupo, Vinyes no volvió a publicar en Bogotá, pero ello tal vez se debió a motivos personales. Sin embargo, también es muy poco lo que se puede citar en cuanto a los jóvenes del grupo.

${ }^{11}$ Germán Vargas, «Fichas sin revisar», en El Nacional (Barranquilla, 15 de marzo de 1948, 2. a sección), pp. 3 y 7.

${ }^{12}$ Germán Vargas, «Sobre el cuento colombiano», en Sábado (Bogotá, núm. 298, 16 de abril de 1949, 3. sección), pp. 25 y 30. Se reeditó en El Heraldo (Barranquilla, 5 de mayo de 1949), pp. 3 y 5.

${ }_{13}$ Alvaro Cepeda Samudio, «Brújula de la cultura», en El Heraldo (Barranquilla, 29 de septiembre de 1951), p. 3.

${ }_{14}$ Alvaro Cepeda Samudio, «El cuento y un cuentista», en El Heraldo (Barranquilla, 11 de abril de 1955), p. 3.

${ }^{15}$ Gabriel García Márquez, «Dos o tres cosas sobre la novela de la violencia», en La Calle (Bogotá, año II, núm. 103, 9 de octubre de 1959), pp. 12-13, y «La literatura colombiana, un fraude a la nación», en Acción Liberal (Bogotá, núm. 2, abril de 1960), pp. 44-47. Cfr. Obra periodística, vol. 4: De Europa y América (Barcelona, Ed. Bruguera, 1983), pp. 763-767 y 787-793.

${ }^{16}$ Ramón Vinyes, "Teatro colombiano de hoy», en El Tiempo (Bogotá, 31 de agosto de 1941, ${ }^{\text {a }}$ sección), pp. 1 y 2 , y «De la literatura catalana», en El Tiempo (Bogotá, 13 de mayo de 1945, 2.a sección), pp. 3 y 4.

${ }_{17}$ Ramón Vinyes, "Conocí a G. K. Chesterton», en Revista de América (Bogotá, vol. II, nứm. 4, abril de 1945), pp. 19-23. 
Aunque vivió en Bogotá por dos épocas (1944-46 y 1949), ejerciendo el periodismo, Alfonso Fuenmayor casi no se manifestó entonces como intelectual y como crítico. Solamente encontramos dos artículos suyos en El Tiempo: uno de juventud y otro de cuando trabajaba en Bogotá, ambos sobre poetas que él apreciaba, y el segundo de esos artículos con intenciones polémicas bastante claras para quien sabe leer entre líneas ${ }^{18}$. A éstos se añadió un tercer artículo aparecido en el semanario Sábado, en el que Fuenmayor se permitía expresar serios reparos ante Luces en el bosque, de Hernando Téllez, mientras el libro suscitaba un concierto de desmedidas alabanzas ${ }^{19}$. Germán Vargas vio una de sus notas de El Mundo de Barranquilla reproducida en la página «Fin de Semana» de El Espectador, que dirigía Eduardo Zalamea Borda ${ }^{20}$. El único texto que entregó especialmente fue el ya citado «Sobre el cuento colombiano», publicado por Sábado, en una sección monográfica de varias páginas dedicada a Barranquilla.

Cepeda Samudio y García Márquez no se manifestaron entonces como críticos ni mucho menos como ensayistas, sino solamente como cuentistas. El primero con «Tap-Room», en el semanario Estampa, entonces coordinado por Alfonso Fuenmayor, y con «Intimismo», en Sábado, en la entrega especial sobre su ciudad ${ }^{21}$. Donde sí colaboraron sistemáticamente algunos miembros del grupo en la prensa bogotana fue a través del reportaje: Alfonso Fuenmayor fue reportero de Cromos, y, a su regreso de Barranquilla, en 1946, asumió la corresponsalía de Semana, un cargo en el que le sucedió Germán Vargas en enero de 1949.

Es decir, que dentro o al lado de la vocación preponderantemente periodística del grupo deben destacarse estos dos rasgos: al desdeñar la práctica del ensayo, se negaron a posar de intelectuales; al participar lo menos posible en las publicaciones bogotanas, evitaron caer en las trampas del sistema del poder intelectual en Colombia. Ambos rasgos llegan a significar una característica fundamental del grupo y a precisar su identidad, incluso con respecto al medio barranquillero, donde sí hubo quien escribió ensayos en abundancia; quien se desvivió por publicar en $E l$

18 Alfonso Fuenmayor, «Camacho Ramírez», en El Tiempo (Bogotá, 14 de enero de 1940, 2. ${ }^{\text {a }}$ sección), p. 4, y «La poesía de Germán Pardo García», en El Tiempo (Bogotá, 30 de diciembre de 1945, 2. ${ }^{\text {a sección), p. } 3 .}$

19 Alfonso Fuenmayor, «El libro de Téllez», en Sábado (Bogotá, núm. 145, 20 de abril de 1946), p. 2.

${ }^{20}$ Germán Vargas, "De la novela colombiana», página 'Fin de Semana', El Espectador (Bogotá, 15 de marzo de 1947). No existe colección de El Mundo, de Barranquilla, correspondiente a 1947.

${ }_{21}$ Alvaro Cepeda Samudio, «Tap-Room», en Estampa (Bogotá, 19 de marzo de 1949), e «Intimismo», en Sábado (Bogotá, 16 de abril de 1949). 
Tiempo y otros órganos de gran difusión, y quien hizo ambas cosas a la vez. De aquí en adelante podemos dedicarnos a una especie de recorrido, muy circunstancial, por los principales ejes del ideario del grupo, relacionados todos con la certeza de que había que vivir en «la hora del mundo».

\section{CONTRA LAS VACAS SAGRADAS Y LOS «LAGARTOS»}

Lo más llamativo, en los discretos pronunciamientos del grupo, lo constituyen sus sarcasmos contra ciertas personalidades poco menos que incuestionables en la Colombia de entonces. Quien haya echado un vistazo al periodismo juvenil de García Márquez habrá podido extrañarse ante la cantidad de alusiones a Augusto Ramírez Moreno, intelectual entonces (1950) encargado de la Embajada colombiana en París. Ramírez Moreno había sido uno de los blancos predilectos de las burlas del grupo en los años anteriores, y García Márquez no hacía sino seguir el ejemplo de sus amigos. Se trataba de destrozar alegremente el mito colombiano del gran orador, cuya encarnación más acabada era justamente Ramírez Moreno. A propósito de éste y de su colega y amigo Silvio Villegas, había escrito Germán Vargas que eran «simpáticas guacamayas» 2 .

El grupo atacaba de la misma manera a todas las vacas sagradas del panorama nacional, en la medida que le aparecían como valores meramente domésticos, endiosados solamente por obra y gracia del aislamiento colombiano e imposibles de exportar. Su víctima por antonomasia fue indudablemente «Calibán» (Enrique Santos Montejo), principal editorialista de El Tiempo, el plumífero más leído del país y encarnación de la mentalidad más reaccionaria en el seno del Partido Liberal. Son más que frecuentes los sarcasmos hacia "Calibán» en las notas del grupo ${ }^{23}$, cuyos miemibros celebraban debidamente sus gazapos, perogrulladas y salidas de tono. Y sobre todo sus ingenuidades de colombiano rancio, despistado por los cambios del mundo contemporáneo. Era la vieja Colombia, la generación «centenarista» que había reinado largos años sobre el país, la que sufría esos sarcasmos a través de «Calibán», y también la Colombia de los

\footnotetext{
${ }^{22}$ Germán Vargas, «Nota intrascendente», en El Nacional (Barranquilla, 18 de febrero de 1948), p. 4.

${ }^{23}$ Por ejemplo, de Alfonso Fuenmayor en su columna 'Aire del día' de $\mathrm{El} \mathrm{He}$ raldo: "Cómo lo lamentamos» (31 de mayo de 1948), "Por tierras de América» (7 de julio de 1948), «La suerte de ciertos regímenes» (1.1 de diciembre de 1948). De Germán Vargas, en El Nacional: "Nota intrascendente» (15 de junio de 1948) y sus «Interlíneas» (21 y 28 de agosto de 1948). De Alvaro Cepeda Samudio: "En el margen de la ruta', «La fobia de Celibán» (El Nacional, 19 de mayo de 1948).
} 
lugares comunes -el país oficial, podría decirse, a pesar de que el liberalismo se encontraba entonces en la oposición.

Otro «centenarista», de menor influencia, como era Luis Ernesto Nieto Caballero, «Lenc», no mereció tantas críticas ${ }^{24}$, pero sí las recibió, en cambio, el sociólogo Luis López de Mesa, que pasaba entonces por ser la conciencia del país en el orden moral y el orden científico y era un cultivador más de la oratoria nacional. A López de Mesa lo consideraba el grupo como otro de esos valores domésticos e inexportables ${ }^{25}$.

Pensaba el grupo que en un tiempo de intenso desarrollo de los medios de comunicación debían desaparecer actitudes propias de la Colombia patriarcal y aislada y desinflarse los prestigios nacionales exageradamente abultados. Pero ese combate debía hacerse extensivo a nuevas generaciones que, desde presupuestos más modernos y con buen conocimiento de los cambios del mundo, pretendían mantener las viejas estructuras y los viejos comportamientos nada más que para aprovechar a su vez las ventajas del poder intelectual. Ello explica que, independientemente o además de su juicio crítico muy negativo, el grupo se ensañara en los voceros del ya decaído movimiento poético «piedracielista», y muy especialmente en su «capitán», Eduardo Carranza. Recordando la asonada crítica de éste contra Guillermo Valencia, Alfonso Fuenmayor decía que

... la cruzada dejó entrever los burdos procedimientos de un racket literario. Y un día, en el desarrollo de una minuciosa estrategia, los jóvenes iconoclastas amanecieron dueños de todas las tribunas del pensamiento ${ }^{26}$.

El caso es que, efectivamente, Carranza, además de ser colaborador asiduo en la Revista de las Indias y del suplemento de El Tiempo, había sido nombrado responsable de éste antes de asumir la dirección de la Biblioteca Nacional ${ }^{27}$. Germán Vargas compartía la misma actitud de Al-

\footnotetext{
${ }^{24}$ Alvaro Cepeda Samudio, 'En el margen de la ruta', «El arte de escribir necrologías', en El Nacional (Barranquilla, 31 de marzo de 1948), p. 4.

${ }_{25}$ Alvaro Cepeda Samudio, en su columna 'En el margen de la ruta', «El idioma del profesor» (hacia el 8 de abril de 1948), «La literatura china» (recorte imposible de fechar). Alfonso Fuenmayor, en su columna 'Aire del día': «Pretensiones críticas» (27 de enero de 1948), «Emilia» (4 de marzo de 1948), una entrega sin título (26 de mayo de 1948). Germán Vargas: 'Nota intrascendente' del 9 de agosto de 1948.

${ }_{26}$ Alfonso Fuenmayor, 'Aire del día', «Un aniversario», en El Heraldo ( 9 de julio de 1948).

${ }^{27}$ Otros ataques de Alfonso Fuenmayor contra Carranza en las entregas de 'Aire del día' correspondientes a los días 20 de enero, 21 de agosto y 15 de septiembre de 1948 y 8 de marzo de 1950 .
} 
fonso Fuenmayor ${ }^{28}$, subrayando con qué facilidad había 1legado Carranza a imitar los comportamientos habituales de la vida intelectual del país:

Hasta ahora, tal vez con la solitaria excepción de Andrés Holguín, de cuya admirable sagacidad aún esperamos tanto, nuestros llamados críticos se han limitado a repetir sobre los poetas nacionales lo que habían dicho sus antecesores en el oficio. Y en esa línea se halla ahora Eduardo Carranza, el arrepentido ${ }^{29}$.

También existía el caso de los escritores estimables que corrían el peligro de echarse a perder entre las fáciles alabanzas y las tentaciones del poder. Alfonso Fuenmayor y Germán Vargas desempeñaban a veces una tarea crítica preventiva. Había sido el caso, de probable eficacia, ya que fue en las páginas de un semanario bogotano donde Alfonso Fuenmayor expresó sus reparos ante el libro Luces en el bosque, de Hernando Téllez. Alegaba Fuenmayor que el libro, como tantos otros en Colombia, no era más que una colección de trabajos periodísticos, muy bien escritos, y que la tarea que debía emprender Téllez tenía que ser de largo aliento y desembocar en una novela.

Pasó lo mismo a propósito de Germán Arciniegas, aunque sin efectos, en la medida que se trató entonces de notas publicadas en Barranquilla. Por encima de sus éxitos, de su poder de jefe de cotizadas publicaciones y hasta de su participación en el poder político, Arciniegas había mantenido un notable sentido de exigencia intelectual y estilística. Al aparecer Biografia del Caribe, Germán Vargas escribió:

Hace apenas unos años comenzó a destacarse en nuestros países un grande escritor colombiano: Germán Arciniegas. Sus últimas obras han sido editadas en Chile, Argentina y México. Su prestigio se extiende por todas las naciones americanas y su nombre figura ya entre los mejores escritores de la América Hispana.

A quienes hemos seguido paso a paso - libro a libro- la ascendente creación literaria de Arciniegas no nos sorprende esta merecida posición de que goza el autor de Los comuneros ${ }^{30}$.

Y concluyó su nota diciendo, con anticipado acierto, que «Arciniegas ha logrado la mejor de sus obras y difícilmente llegará a superarla». Poco después, Alfonso Fuenmayor celebraba el ingreso del escritor a la Acade-

${ }^{28}$ Germán Vargas, 'Interlíneas', en El Nacional (2 de junio de 1948).

${ }^{29}$ Germán Vargas, 'Interlíneas', en El Nacional (30 de agosto de 1948).

${ }^{30}$ Germán Vargas, «Un hermoso libro de aventuras», en El Heraldo (Barranquilla, 22 de junio de 1946,2 . $^{a}$ sección), p. 1. 
mia colombiana y ponía de relieve la novedad que significaba su obra con relación a lo que solía ser la disciplina histórica en el país («una cosa tradicionalmente muerta, un código de fechas»), alegrándose de que por fin hubiera "un académico antiacadémico» ${ }^{31}$.

Menos de dos años después, cuando ya nadie hubiera criticado a Germán Arciniegas, los dos periodistas barranquilleros no vacilaron en hacerlo tan pronto como les pareció que decaía la calidad de su producción, y dieron entonces una señal de alarma. Germán Vargas, tras recordar la calidad de Biografía del Caribe y repetir su juicio de 1946 («Difícilmente... puede superar esa espléndida síntesis de toda su obra»), tenía que proferir un juicio negativo:

Quizás comprendiéndolo así, Arciniegas ha regresado a lo que fue su iniciación literaria: las notas periodísticas. Recientemente, El Tiempo publicó sus apuntes sobre el viaje que Arciniegas realizó por la Europa devastada. Pero ni en estas breves notas ni en las lentas y tontas que ahora publica sobre sus «Recuerdos de infancia» están presentes la frescura y la gracia de sus estupendos apuntes sobre los Estados Unidos. Y la falta de esta presencia la lamentamos cordialmente todos los admiradores de Germán Arciniegas ${ }^{32}$.

Por su parte, ante los mismos texos (que eran, efectivamente, pésimos), Alfonso Fuenmayor expresaba la misma decepción, con mordaz ironía, refiriéndose además a la adulación indiscriminada que solía rodear cuanto publicaban los grandes nombres del país:

Germán Arciniegas, en muchas ocasiones con innegable justicia, ha sido un niño mimado de la crítica. Todo cuanto ha hecho o escrito ha sido saludado, por lo menos en nuestro país, con excesivas muestras de admiración. Probablemente de aquí nazca el inconsciente convencimiento de que cuanto él hace ha de ser, por simple fuerza de inercia, excelente ${ }^{33}$.

No había, pues, prestigio definitivo ni indiscutible para los miembros del grupo de Barranquilla, y esas notas de crítica desprejuiciada bastaban, dadas las convenciones de la vida intelectual del país, para hacer de ellos iconoclastas tranquilos, pues del nulo impacto de sus notas, si salían en Barranquilla, podían derivar la más perfecta tranquilidad.

${ }^{31}$ Alfonso Fuenmayor, 'Aire del día', «Arciniegas en la Academia», en El Heraldo (11 de julio de 1946), p. 3.

${ }^{32}$ Germán Vargas, 'Nota intrascendente', en El Nacional (Barranquilla, 7 de febrero de 1948), p, 4.

${ }^{33}$ Alfonso Fuenmayor, 'Aire del día', «Unas memorias», en El Heraldo (Barranquilla, 24 de febrero de 1948), p. 3. 
Si las vacas sagradas recibían sus dardos, otro elemento del zoológico intelectual le inspiraba al grupo más sarcasmos aún: el «lagarto», o sea, el intrigante, el que a base de amiguismos, recomendaciones e intercambios de favores, logra que se le tenga en cuenta para figurar, donde sea, pero especialmente en la prensa y en las publicaciones literarias. A ese animal mitológico y cotidiano dedicó Germán Vargas una muy divertida nota titulada «Defensa del lagarto» ${ }^{34}$.

Como la «lagartería» literaria solía nutrir buena parte de las publicaciones de prestigio, especialmente las del suplemento de El Tiempo, los miembros del grupo prestaron una atención proporcionalmente mínima a sus estragos, que eran una realidad más o menos semanal. Sólo de vez en cuando brincaba uno de ellos ante una manifestación excesiva, como lo hizo, por ejemplo, con inusitada virulencia, el muy plácido Alfonso Fuenmayor ${ }^{35}$. Por lo general, reservaban sus ironías para las ocasiones en que la «lagartería»se salía de las páginas de la prensa y trataba de convertirse en espectáculo: cuando se habló en Barranquilla de repatriar al poeta local Leopoldo de la Rosa, quien agonizaba, indigente, en México ${ }^{36}$; cuando el club local de «mujeres intelectuales» promovió debates, no tanto por plantear o resolver problemas como por debatir públicamente ${ }^{37}$; o cuando se reunía en Bogotá un Congreso de Intelectuales Nuevos, mientras en el Congreso de verdad, el de Representantes y Senadores, las minorías conservadoras disparaban y mataban. A la distancia, el congreso del que se burló Alfonso Futenmayor aparece como algo efectivamente inflado, aunque es cierto que algunos de sus participantes - Gómez Valderrama, Gaitán Durán - han dejado una huella duradera en la literatura del país. Pero con sobrada razón, mientras el país estaba llegando al clímax de la violencia política, podía escribir Alfonso Fuenmayor:

Fue una gran oportunidad para pronunciar bellos discursos, para jugar al presidente, al vicepresidente y para conmemorarlo por medio de fotografías no exentas de cierta majestuosa grandeza.

${ }^{34}$ Germán Vargas, «Defensa del lagarto», en El Mundo (Barranquilla, 1 de noviembre de 1946), p. 4.

${ }^{35}$ «Pretensiones críticas». Cfr. nota 25. Alfonso Fuenmayor aludía al ensayo «Imitación y creación en la literatura colombiana», de Daniel Arango, aparecido dos días antes en el suplemento de El Tiempo.

${ }^{36}$ Alfonso Fuenmayor, 'Aire del día', «Regreso de Leopoldo de la Rosa», en $E l$ Heraldo (2 de marzo de 1948), p. 3. Y Germán Vargas, 'Nota intrascendente', en El Nacional (3 de marzo de 1948), p. 4.

37 Alfonso Fuenmayor, "Aire del día', «Mujeres en acción», en El Heraldo (28 de febrero de 1948), p. 3, y «En el campo femenino» (6 de julio de 1948). Germán Vargas, 'Nota intrascendente', El Nacional (22 de marzo de 1948), p. 4. 
Es difícil concebir algo más grave que el temario discutido por los miembros del Congreso. En este sentido apenas puede ser superado por las conclusiones a que llegaron. No se escapó de su sagaz visión ningún problema humano.

Pero si, efectivamente, se trataba de conseguir efectos distintos de la emoción oratoria, de las buenas y envidiables fotografías, del placer de presentar «proposiciones», el Congreso de Intelectuales puede considerarse un fracaso. Claro que un fracaso divertido ${ }^{38}$.

En algunos casos, la expresión llegaba a ser más benigna, aunque los miembros del grupo pensaran lo peor de ciertos actos o proyectos inútilmente aparatosos. Así pasó, por ejemplo, con el proyecto concebido por la directora de Extensión Cultural de Barranquilla, la escritora Olga Salcedo de Medina, de «coronar» al poeta local Miguel Rasch Isla. La reprobación de Alfonso Fuenmayor, para quien sabía leerlo, debía resultar patente, pero su humor - y la necesidad de no alborotar demasiado el ambiente de la ciudad- lo llevaba a sugerir su horrorizado rechazo a esa pintoresca idea antes que a expresarlo. Solamente decía Alfonso Fuenmayor:

Iniciado junto con la generación del centenario -palabra esta que los jóvenes pronuncian con la sonrisa benévola del perdonavidas-, Miguel Rasch Isla ha sido un ejemplo de constante laboriosidad (...), un ingeniero de la retórica y un hombre curtido por una dilatada experiencia literaria ${ }^{39}$.

El pensamiento crudo del grupo, en este caso, lo podemos conocer gracias a una carta (10 de mayo de 1950) de Germán Vargas al «sabio catalán»:

Olga (...) prepara para diciembre algo tan anacrónico como la coronación del más anacrónico portalira (?) barranquillero: don Miguel Rasch. Y el puñetero (iviva el barranquillerismo!) viejo se va a dejar... Vamos a tener que pedir que le den a ella la Medalla Cívica a ver si se aquieta.

La idea de coronar a un poeta, como muchos años antes se había coronado a Julio Flórez, era, efectivamente, anacrónica en lo que era el quin-

${ }^{38}$ Alfonso Fuenmayor, 'Aire del día', «Congreso artístico», en El Heraldo (26 de septiembre de 1949), p. 3.

${ }^{39}$ Alfonso Fuenmayor, “Aire del día», «Una coronación», en El Heraldo (26 de abril de 1950), p. 3 . 
to año de la época atómica. Pero todo lo que hemos venido viendo a propósito de vacas sagradas y «lagartos» no era más, de parte del grupo, que una protesta contra los anacronismos colombianos. Ese trasfondo cayó hoy en el olvido, pero está ligado al concepto de la modernidad necesaria que defendía el grupo.

\section{EL BOMBO MUTUO Y LA LITERATURA COLOMBIANA}

Solidario con el juego del elogio indiscriminado, existía en la vida literaria del país otro juego que muchos, no solamente el grupo, llamaban el «bombo mutuo». Nada más asomarse al periodismo lo habían conocido los miembros del grupo. En los años cuarenta, Ramón Vinyes lo mencionaba en sus escritos secretos, mientras tenía que pagar su tributo al sistema con algunas entregas de sus columnas de prensa. El primero en mencionarlo entonces, muy de paso, fue José Félix Fuenmayor en una interesante evocación del pasado literario de Barranquilla, que es también uno de los poquísimos textos que publicó en esos años ${ }^{40}$.

Las alusiones del grupo al fenómeno del bombo mutuo menudean a partir de 1948. Alfonso Fuenmayor escribía:

Lo que ha dado en llamarse muy certeramente la cofradía del mutuo bombo es algo más que una generosa asociación de dispensadores de elogios; es también, y en grado eminentísimo, una industria que no tarda en pagar buenos dividendos a los favorecidos tenedores de acciones.

La sede de esta razón social es la capital, y sus habituales órganos de publicidad son los periódicos de allí, detrás de cuyas columnas están apostados los ditirámbicos accionistas en una enternecedora empresa de reciprocidad y cooperación.

Cada día del año trae para los asociados de esta vasta y fraternal organización un vehemente elogio destinado para el genio que un riguroso turno señala. Si uno de ellos escribe algo que con excesiva buena voluntad se puede tomar por filosofía, no se tardará, para relievar los méritos del galardonado, en recurrir a la descomedida comparación con Kant o Husserl. Si en cambio es alguien que dispone las palabras en angostas líneas, se trata de un poeta que, para enjuiciarlo críticamente, hay que tratarlo como si fuese el mismo Baudelaire ${ }^{41}$.

40 José Félix Fuenmayor, «Pasatiempos de Gómez Jarab. Recuerdos de una vida literaria barranquillera», en El Heraldo (28 de octubre de 1943, 4. sección), p. 1.

${ }^{41}$ Alfonso Fuenmayor, "Aire del día', "Una sociedad anónima», en El Heraldo (27 de febrero de 1948), p. 3. 
También Germán Vargas y Alvaro Cepeda Samudio se refirieron al tema, con menos detenimiento, pero con igual humor ${ }^{42}$.

Esos hechos, a los que los periodistas barranquilleros, encargados de columnas de comentario, debían dar alguna importancia, no les hacían perder de vista lo esencial, es decir, el estado de la literatura nacional. Herederos de la tradición local, sabían mirar hacia afuera y establecer comparaciones de calidad, las cuales les señalaban el porqué del desconocimiento que sufría la literatura colombiana en el exterior. Ese era un tema abundantemente tratado en las publicaciones del país: ¿Por qué nos desconocen? Son múltiples sus manifestaciones, bajo formas variables, en la prensa de los años cuarenta. La respuesta que se le solía dar a la pregunta señalaba muchas veces la escasa difusión del libro colombiano, y la culpa, se decía casi siempre, recaía en los gobernantes, que no le prestaban a la cultura el debido apoyo, sea en la misma difusión, sea al no ayudar materialmente a los escritores en sus trances creativos. Casi nunca se pasaba de allí, y eran muy pocos los que admitían que si los escritores colombianos no trascendían las fronteras nacionales era porque sus obras, generalmente, no valían la pena. Hubiera sido difícil proferir semejante afirmación para quienes justamente dedicaban su tiempo a repartir sus elogios entre colegas que, a su vez, retribuirían ese favor. Sólo quienes no participaban en el juego del bombo mutuo podían insinuar las verdaderas razones de ese estancamiento; principalmente Eduardo Zalamea Borda y Hernando Téllez. Sin intereses creados y, además, protegidos por la cuasi inexistencia de sus notas de $E l$ Heraldo y El Nacional, los barranquilleros tenían más libertad que los dos citados críticos bogotanos para llamar a las cosas por su nombre y para preocuparse por los valores exportables. Podían decir más crudamente que Bogotá no era de ninguna manera la tan mentada «Atenas sudamericana» ni Colombia un país de escritores.

Al principio enmascararon un poco sus desoladas convicciones. Así era como, en su ya citada nota sobre Biografía del Caribe, Germán Vargas decía que había una «injustificada situación de desconocimiento», y que al lado del caso de la excelente novela de Eduardo Zalamea Borda Cuatro años a bordo de mí mismo "podrían multiplicarse los ejemplos». Era una forma demasiado sutil de decir las cosas, a la que Germán Vargas renunció en adelante: sus notas de 1948 y 1949 eran más directas, sin dejar de usar formulaciones llenas de cruel humor. Alfonso Fuenmayor, como Alvaro Cepeda Samudio, pero de manera más insistente, fue expresando la opinión del grupo sobre la literatura colombiana de su tiempo; pensaba

${ }^{42}$ Germán Vargas, 'Nota intrascendente', en El Nacional (29 de marzo de 1948), p. 4. Cepeda Samudio: la citada nota «Nuestra actividad literaria». 
que, en realidad, no existía tal literatura ni podía existir por varias razones: la elevada tasa de analfabetismo del país, la ausencia o la extremada escasez de verdaderos escritores, la nulidad del sistema editorial y la consiguiente inutilidad de la crítica. No existían sino obras aisladas que no llegaban a configurar una literatura ${ }^{43}$. En lo que le importaba, la narrativa, Cepeda Samudio era más directo. La primera nota de tema literario que publicó en la prensa adulta - fue antes de su primer contacto con el grupo- proclamaba la suma indigencia de la narrativa colombiana:

Abre Eduardo Zalamea Borda una muy interesante encuesta en su «Fin de Semana» de El Espectador. La pregunta es sencilla y concreta: «¿Qué novelas colombianas, en número de diez, cree usted que deberían ser traducidas al inglés?» A primera vista, la pregunta se absuelve con pasmosa rapidez: - No diez, veinte novelas colombianas podrían ser traducidas con éxito al inglés. Pero cuando entramos a ver cuáles son las novelas que podrían ser traducidas al inglés - con éxito económico y literario, se entiende- éstas no aparecen por ninguna parte (...). Las novelas colombianas que podrían traducirse con éxito al inglés se pueden contar con los dedos de una mano... y sobran dedos ${ }^{44}$.

Esa era la piedra de toque en los juicios estéticos del grupo: la confrontación con los valores extranjeros. El grupo pertenecía a la minoría de intelectuales colombianos que, a salvo de los efectos del bombo mutuo, establecían la sana comparación que nadie debería haber ignorado.

\section{CONTRA LOS CALDENSES Y EL NACIONALISMO LITERARIO}

Los escritores caldenses —oriundos del departamento andino de Caldas- eran uno de los blancos predilectos del grupo, a la vez porque a éste le parecían como el nec plus ultra de la mediocridad literaria nacional y porque constituían un grupo dominante en la prensa y el mundo intelectual: reinaban sobre la odiada oratoria, sobre la cuentística, sobre los suplementos literarios y las páginas editoriales de El Tiempo, colándose además en los semanarios y en cuantas revistas podían. En los cal-

${ }^{43}$ Alfonso Fuenmayor en las siguientes entregas de 'Aire del día': «La ignorada Colombia» (16 de enero de 1948), «Cuatro años a bordo de mí mismo» (28 de enero de 1948), "La crítica» (10 de enero de 1950), «La esterilidad literaria» (20 de marzo de 1950), "Una razón más» (4 de abril de 1950). El 20 de enero de 1948, en la entrega titulada «Nuestra literatura», afirmaba: «Queremos (...) que nuestros literatos estudien.»

${ }^{44}$ Alvaro Cepeda Samudio, 'Cosas', «Intermedio», en El Heraldo (12 de marzo de 1947), p. 6. 
denses se combinaban varios de los elementos que suscitaban las iras del grupo.

En 1947 escribía Garmán Vargas:

Si por literatura caldense se entiende el exceso verbalista, el uso y el abuso de una vana y exuberante palabrería a que la han conducido la falsa sonoridad de Silvio Villegas y la frondosidad tropical de Arias Trujillo... ${ }^{45}$

Y el mismo, en 1948:

El departamento de Caldas, uno de los más pequeños en extensión, es uno de los más feraces en la producción de políticos de desorbitado lirismo que han hecho carrera en el país con la materia prima de sus discursos aprendidos de memoria. En general, son oradores, ante todo. Sus libros son discursos sonoros y vibrantes, y cuando se les lee - como dijera alguien-, es necesario cerrar el libro, al terminar un párrafo emocionante, para oír los aplausos ${ }^{46}$.

Pero, aparte de la frondosidad verbal de los «greco-caldenses», de la que también se burlaba Alfonso Fuenmayor y se burlaría García Márquez, el departamento de Caldas ejercía una verdadera tiranía sobre la cuentística. Como se trataba de un ramo en el que el grupo veía una gran posibilidad de renovación literaria - la novela vendría después-, los cuentistas caldenses fueron objeto de ataques más minuciosos y argumentados ${ }^{47}$.

Tres de esos cuentistas ocupaban un espacio desproporcionado en las páginas de suplementos y revistas: Eduardo Arias Suárez, Adel López Gómez y Antonio Cardona Jaramillo; para los dos últimos existía el agravante de que eran entonces colaboradores «de planta» de El Tiempo. Eran entonces los autores más productivos o los que mejor acogida recibían en suplementos y revistas. Sin haber efectuado una revisión exhaustiva de las publicaciones literarias, encontramos que en los años cuarenta López Gómez publicó unos cincuenta y seis cuentos; Arias Suárez, unos treinta y siete, y Cardona Jaramillo, unos cuarenta y seis - cifras que están forzosamente por debajo de la realidad-. Con sus artículos de prensa, las en-

${ }^{45}$ Germán Vargas, «Palabras sobre Oscar Echeverry Mejía», en El Heraldo (18 de octubre de 1947), p. 9.

${ }^{46}$ Germán Vargas, 'Nota intrascendente', El Nacional (4 de junio de 1948), p. 4.

${ }^{47} \mathrm{El}$ cuento fue uno de los objetos principales de las reflexiones y los debates del grupo de Barranquilla. A ello nos hemos referido en una ponencia leída en el Congreso Internacional sobre el Cuento Latinoamericano, reunido en la Sorbona en mayo de 1981. Cfr. Jacques Gilard, «El grupo de Barranquilla y la renovación del cuento colombiano», en Ibérica, Les Cahiers (París, núm. 1, 1983), pp. 55-72. 
trevistas que unos a otros se hacían, las autoentrevistas y las reseñas que suscitaban sus libros llegaban a ser una presencia sofocante en la narrativa del momento. Curiosamente, en una autoentrevista, Adel López Gómez se quejaba del mal trato que recibían los cuentistas «nacionales» en las publicaciones del país:

Los publicistas se desentienden de la producción de cuentos propios para dar cabida a los extranjeros en sus páginas de honor ${ }^{48}$.

Más motivos de queja podían tener ciertos lectores, los que no apreciaban esa cuentística representada por López Gómez. Continuaba éste:

Por lo demás, nuestro cuento es original y propio, impregnado del color y el sabor de la tierra, moldeado de primera mano en su paisaje (...). Influencia, claro que existe. Un buen cuentista tiene por fuerza que tener alguna reminiscencia de Maupassant, de Daudet, de Pirandello, de Quiroga, de todos. Son o pueden ser influencias de técnica, de procedimientos, de semejanza en los tipos. Pero los nuestros son fieles a su medio y a su humanidad.

Al afirmar lo anterior, López Gómez se refería al cuento colombiano, pero como había escrito previamente: "Toda la cuentística colombiana está localizada en Caldas», no salía de su ámbito regional. Y saltan a la vista la confusión de lo nacional con lo local y con lo rural, la creencia de que influencias viejas - por el mero hecho de ser viejas- no afectaban la identidad de los textos, la incapacidad para pensar en posibles influencias nuevas. Por su parte, Antonio Cardona Jaramillo señalaba como colombiano el «cuento lleno de tierra" que él mismo escribía, así como López Gómez y Arias Suárez ${ }^{49}$, ese cuento que se solía definir como "terrígena» o «terrígeno», un adjetivo que irritaba a Germán Vargas.

En esas posturas se daba un caso espectacular de estancamiento ideológico y estético. Tanto Germán Vargas como Alfonso Fuenmayor se burlaron de ese particularismo caldense y de sus trasnochados criterios por reacción de costeños, por estar convencidos de que el mundo rural ya no constituía un alimento digno para la literatura -convicción esta nada indiscutible - y sobre todo por pensar que ya era tiempo de que los escritores colombianos se fijaran en corrientes literarias extranjeras más con-

\footnotetext{
${ }^{48}$ Adel López Gómez, «De los cuentos y los cuentistas», en El Tiempo (Bogotá, 4 de marzo de 1948), p. 5.

49 Anónimo, "Desaparece el cuento en Colombia» (entrevista con Antonio Cardona Jaramillo), en El Tiempo (20 de junio de 1948, 2. sección), p. 3.
} 
temporáneas ${ }^{50}$. Los del grupo defendían el concepto de que los mejores cuentos colombianos eran obras de escritores no especializados en el género ${ }^{51}$.

Se trataba de un combate que no era solamente contra los caldenses, sino contra lo que aún entonces se llamaba «el nacionalismo literario». Esta doctrina había surgido en 1941 a raíz de un concurso de cuentos organizado por la Revista de las Indias, en el que se habían enfrentado, finalmente, un relato de Jorge Zalamea, «La grieta», y otro de Eduardo Caballero Calderón, «Por qué mató el zapatero». El cuento de Zalamea era una suerte de herejía: relataba la vida de un obrero irlandés y su acción se desarrollaba en Dublín. La filiación literaria, aun escandalosamente exótica, era evidente, pero del concurso había nacido una violenta polémica en la que se había destacado el escritor Tomás Vargas Osorio, partidario ardiente del «nacionalismo literario»; exigía que los temas y los procedimientos fueran exclusivamente colombianos, sin especificar qué podía ser un procedimiento «nacional», con una saña tanto más curiosa cuanto que él mismo era autor de excelentes cuentos que superaban en mucho los estrechos criterios que defendía. A ello se refería Germán Vargas cuando hablaba de «una curiosa y tonta polémica sobre nacionalismo literario», en su nota «Fichas sin revisar», y elogiaba los cuentos de autores nuevos, especialmente uno de Gustavo Wills Ricaurte, por ser «muy norteamerciano» ${ }^{52}$, y celebraba el "claro sentido universalista» de Wills, Laguado, Cepeda Samudio y García Márquez, en su nota "Sobre el cuento colombiano».

\section{LiterATURA EXTRANJERA}

Al contrario de los partidarios del nacionalismo literario, los miembros del grupo pensaban que las letras nacionales no podían progresar si no acogían valores foráneos. Lo más claro es su admiración por la narrativa americana contemporánea. De ello tenemos noticias tan pronto como los más jóvenes empiezan a escribir con regularidad en la prensa; pero

${ }^{50}$ Germán Vargas, 'Nota intrascendente', El Nacional (22 de junio de 1948), p. 4.

${ }^{51}$ Alfonso Fuenmayor, 'Aire del día', «Sobre el cuento», en El Heraldo (5 de marzo de 1948), p. 3. Germán Vargas, «Sobre el cuento colombiano», en Sábado (Bogotá, 16 de abril de 1948). Ramón Vinyes retomaba la idea en una entrevista que le hizo Javier Auqué Lara para el Dominical de El Espectador en enero de 1949. Cfr. Selección de textos, op. cit., tomo II, p. 385.

${ }^{52}$ Germán Vargas, 'Nota intrascendente', El Nacional (14 de agosto de 1948), p.5. 
mucho antes, Ramón Vinyes había escrito algo sobre Faulkner ${ }^{53}$, al que había leído en Barcelona en los años treinta y en su exilio francés, antes de regresar a Colombia. Ese activo y proselitista interés por la literatura de Estados Unidos aparece cuando Alfonso Fuenmayor traduce un cuento de Hemingway, en $1945^{54}$. Hacia finales del mismo año, al reseñar un libro de ensayos de un joven intelectual de Barranquilla, un estudio sobre Gallegos, Rivera y Güiraldes sugería Germán Vargas:

Sería de grande interés un ensayo posterior en el que el autor sacara conclusiones sobre los puntos de vista esbozados en los tres estudios iniciales, generalizando sobre la novelística americana y estableciendo similitudes y desigualdades entre la novela hispanoamericana y la novela de Estados Unidos, sorprendente por sus temas y por su téenica ${ }^{55}$.

Con ello demostraba Germán Vargas que lo que aún se consideraba como lo mejor de la literatura hispanoamericana le parecía sumamente atrasado con relación a la del Norte. En 1948, mientras se discutía en Colombia si la influencia anglosajona debía reemplazar la francesa, escribió:

No podría negarse que la más interesante producción novelística está hoy en Norteamérica. Y que difícilmente, salvo en Inglaterra, pueden encontrarse en la actualidad novelistas como Faulkner, como Caldwell, como Upton Sinclair (...). Lo cierto es que hasta ahora la influencia norteamericana no se ha concretado en expresiones culturales colombianas ${ }^{56}$.

Germán Vargas sugería entonces lo que García Márquez afirmaría abruptamente en 1950. Por ejemplo:

Todavía no se ha escrito en Colombia la novela que esté indudable y afortunadamente influida por Joyce, por Faulkner o por Virginia Woolf. Y he dicho "afortunadamente», porque no creo que podríamos los colombianos ser, por el momento, una excepción al juego de las influencias ${ }^{57}$.

${ }^{53}$ "Vísperas de Navidad: un autor» (El Heraldo, 27 de diciembre de 1940). Cfr. Selección de textos, op. cit., tomo I, pp. 356-358.

${ }^{54}$ Se trataba de «The Killers». La traducción apareció bajo el título «Los asesinos» en Revista de América (vol. IV, núm. 10, octubre de 1945), pp. 144-152. La volvió a utilizar Alfonso Fuenmayor en Estampa (1949) y Crónica (1950).

${ }^{55}$ Germán Vargas, «El libro de Mario Madrid-Malo», en El Heraldo (19 de noviembre de 1945), p. 3.

${ }^{56}$ Germán Vargas, 'Nota intrascendente', El Nacional (7 de junio de 1948), p. 5.

57 Gabriel García Márquez (Septimus), «¿Problemas de la novela?», en El Heraldo (24 de abril de 1950). Cfr. Obra periodística, vol. 1: Textos costeños, op. cit., pp. 267-269. 
O, a propósito de Arturo Laguado, y refiriéndose solamente a los escritores de Estados Unidos:

Nadie está tan distante de los cuentistas norteamericanos como el autor del Granguiñol. Y a última hora, pienso yo, ésa podría ser una de sus pocas fallas ${ }^{58}$.

Alfonso Fuenmayor, por su parte, también estaba convencido de la validez potencial de los modelos extranjeros. Lo había demostrado en 1945 su traducción de un cuento de Hemingway, y él se expresaba también en términos encomiásticos sobre Faulkner ${ }^{59}$, como lo había hecho tardíamente Ramón Vinyes, algo influido entonces por sus jóvenes amigos ${ }^{60}$. Más claramente de lo que lo hicieron Germán Vargas y Cepeda Samudio, y tanto como lo haría García Márquez, Fuenmayor se manifestó como partidario de la influencia extranjera sobre la literatura colombiana, pero era solamente una cuestión de expresión, porque todos estaban de acuerdo y algunos de ellos solamente insinuaban lo que los otros expresaban. Fue el caso a propósito de Sartre:

Como un camino de salvación sería de desear la vulgarización de la obra de Sartre en Colombia... ${ }^{61}$

O un poco más tarde:

Esa influencia (de Sartre) no existe, desgraciadamente (...). Tenemos. que lamentar que eso no ha sucedido ${ }^{62}$.

Esta línea de apertura hacia lo foráneo se confirmaría con la publicación del semanario del grupo, Crónica, del que cada entrega - al menos en la época interesante, de abril a diciembre de 1950 - proponía un cuento extranjero, y seguiría luego con la columna «Brújula de la cultura», que Cepeda Samudio mantendría en El Heraldo, de Barranquilla, de septiembre a noviembre de 1951 .

${ }^{58}$ Gabriel García Márquez (Septimus), «Otra vez Arturo Laguado», en El Heraldo (27 de abril de 1950). Cfr. Obra periodística, vol. 1: Textos costeños, op. cit., pp. 273-274.

${ }^{59}$ Alfonso Fuenmayor, 'Aire del día', «Un novelista político», en El Heraldo (Barranquilla, 22 de noviembre de 1949), p. 3.

so «Sartre vs. Faulkner», en El Heraldo (26 de abril de 1949). Cfr. Selección de textos, op. cit., tomo I, pp. 490-492.

${ }^{61}$ Alfonso Fuenmayor, 'Aire del día', «A propósito de una obra de Sartre», en El Heraldo (20 de enero de 1948), p. 3.

${ }^{62}$ Alfonso Fuenmayor, 'Aire del día', «Todavía Europa», en El Heraldo (8 de marzo de 1950), p. 3. 
¿Tenía el grupo mejor información que los intelectuales del centro del país? La tradición local, sumada a la vocación periodística de sus miembros, constituyen una razón válida para pensarlo. Por ejemplo, no deja de resultar asombroso que, habiendo aparecido Bestiario en marzo de 1951, Alvaro Cepeda Samudio pudiera escribir un breve elogio de Cortázar (nada de ensayos) en una fecha tan temprana como agosto de ese mismo año:

Cuentos.-Ha llegado a Colombia el último libro del extraordinario cuentista Julio Cortázar. Bestiario, en la mejor tradición de Felisberto Hernández y Norah Lange, presenta una serie de cuentos en los cuales la línea que divide la realidad de la irrealidad ha desaparecido ${ }^{63}$.

La curiosidad sistemática explica que, a través de la Librería Mundo, de su amigo Jorge Rondón, el grupo haya tenido noticia de la salida del libro y lo haya encargado. Pero es evidente que a ello se añadió otro hecho, de igual, si no mayor, importancia: una lectura con total acierto crítico, el cual se debió a la buena preparación del grupo y a su claro sentido de las corrientes contemporáneas.

Esto último es lo que explica el notable desajuste cronológico que separa los descubrimientos literarios de Barranquilla y los de Bogotá. Es ejemplar, a este respecto, el caso de Borges. Los del grupo no disponían de una ventaja desmedida con relación a los intelectuales de la capital. La revista Sur les llegaría a lo sumo un par de semanas antes de llegar a Bogotá. La revista la conocían todos, al menos porque en ella escribía Arciniegas, su único verdadero colaborador colombiano (mucho antes de Jorge Gaitán Durán y Alberto Zalamea, que muy poco escribieron en ella). Nadie, ni el mismo Arciniegas, se fijó en la calidad fuera de lo común de algunos escritores rioplatenses que colaboraban en Sur; si algo se reproducía de vez en cuando en la Revista de las Indias, no eran ciertamente textos de Borges. Sobre éste sólo encontramos, en El Tiempo, un breve artículo de orientación filosófica dedicado a su poesía por Danilo Cruz Vélez ${ }^{64}$. Y nada más en todos los años cuarenta: ni análisis, ni reproducción de un cuento, un poema o un ensayo ni reseña. En Barranquilla, Ramón Vinyes leía a Borges - como consta en sus cuadernos de apuntes- en 1941 y 1942. Lo evocó en una columna de El Mundo, en 1946, y también lo hizo entonces Germán Vargas, jefe de redacción de ese mismo

${ }^{63}$ Alvaro Cepeda Samudio, 'Brújula de la cultura', El Heraldo (31 de agosto de 1951), p. 3.

${ }^{64}$ Danilo Cruz Vélez, «Jorge Luis Borges», en El Tiempo (Bogotá, 9 de julio de $1939,2{ }^{2}$ sección), p. 2. 
diario barranquillero ${ }^{65}$. En 1950, Crónica reprodujo «Emma Zunz» y «La forma de la espada». Fue solamente en 1951 cuando el dominical de $E l$ Espectador reeditó este último cuento ${ }^{66}$, y solamente en 1952 cuando, en su columna dominical de El Tiempo, Pedro Gómez Valderrama dedicó un análisis a Borges ${ }^{67}$. Más ejemplar aún sería el caso de Felisberto Hernández, también leído tempranamente por Vinyes, y de quien Crónica reprodujo dos cuentos en 1950: «Nadie encendía las lámparas» y «Muebles 'E1 Canario'", mientras en toda la época consideraba (1937-1956) no encontramos ninguna alusión al gran escritor uruguayo en la prensa y las revistas de Bogotá.

\section{Un CONCEPTO DE AMÉRICA}

Alfonso Fuenmayor, reaccionando ante una afirmación del muy leído crítico peruano Luis Alberto Sánchez («Seguimos siendo imitadores»), escribió en 1950:

Sería bueno recordar que el americano es uno de los pocos tipos humanos que tienen derecho, y no un derecho cualquiera, sino un derecho que pudiéramos llamar biológico, para aceptar ciertas influencias que en ningún caso le son ajenas. El americano es, un poco, muchas cosas. Si examinamos la historia, las sucesivas emigraciones que han llegado hasta esta parte del Atlántico, se comprendería, de una vez por todas, que nuestra aberración sería pensar y sentir exclusivamente como lo hicieron Guautémoc o Atahualpa. Si aceptamos la luz eléctrica, tenemos que aceptar a William Faulkner. Si el whisky nos dice algo, también nos dice algo James Joyce ${ }^{68}$.

La tradición local, una vez más, ayudaba a que así se pensara en el grupo, al mismo tiempo que las convicciones y los juicios estéticos. Por ello existía ese rechazo a las posturas del nacionalismo, literario o no. América no era, para los del grupo, ese terruño entrañable de los cuentistas caldenses y tampoco era ese mundo grandioso evocado por la narrativa del telurismo.

${ }^{65}$ Ramón Vinyes, «Apunte al margen», en El Mundo (27 de agosto de 1946). Cfr. Selección de textos, op. cit., tomo II, pp. 423-424. Germán Vargas, «Marinos argentinos», en El Mundo (Barranquilla, 13 de agosto de 1946), p. 4.

${ }^{66}$ Dominical de El Espectador (Bogotá, 6 de mayo de 1951), p. 6.

${ }^{67}$ Pedro Gómez Valderrama, 'Los pasos perdidos', «La muerte y la brújula», en El Tiempo (Bogotá, 23 de marzo de 1952, 2. ${ }^{\text {a sección), p. } 2 .}$

${ }_{68}$ Alfonso Fuenmayor, "Aire del día', "Americanos universales», en El Heraldo (12 de abril de 1950), p. 3. 
De esta última nacía, sin embargo, la imagen de América que entonces predominaba en Colombia. Si se creía que lo colombiano estaba en el mundo apacible de los cuentos pueblerinos - arcaísmo, orden patriarcal-, ello no impedía que se pensara que la realidad americana estaba en las grandes novelas de la Sierra, la Selva y la Pampa. Rivera, al hablar de un territorio que, sin embargo, era colombiano, había introducido en la narrativa nacional una realidad más bien exótica, que se aceptaba - icómo habría sido posible rechazarla?-, pero que no dejaba de inquietar. Sólo que, de todas maneras, constituía el lazo con el resto del continente Sur, el vínculo con Gallegos, Güiraldes, Alegría y los novelistas ecuatorianos. Esa era la América que se aceptaba y acataba, y no la de Borges, Onetti o Felisberto.

El grupo de Barranquilla no admitía esa visión. Según una tendencia frecuente entonces, pero escasamente representada en Colombia, quería que la literatura se libertara del peso de la geografía y mirara hacia el hombre. Antes de que, en 1950, García Márquez expresara sus reticencias ante la candidatura de Rómulo Gallegos al premio Nobel ${ }^{69}$, y hablara de «esa cosa que se llama $L a$ vorágine» ${ }^{70}$, sus amigos ya habían manifestado su convicción de que debían superarse los tiempos del telurismo. El entusiasmo de Germán Vargas ante Biografía del Caribe era por el humor que alentaba en ese libro, por la extravagancia y el cosmopolitismo del mundo evocado, y decía, en una nota ya citada, al evocar el descenso estético de los escritos posteriores de Arciniegas:

... el personaje central de la obra de Arciniegas es la América nuestra, extraña mezcla de blanco y negro e indio, toda esta mulatería que se fue formando en el Nuevo Mundo cuando los españoles comenzaron el «descubrimiento» de América.

Hablar de «mulatería», aceptar y exaltar el mestizaje caribeño, era entonces una audacia que iba más lejos incluso que el propio libro comentado. Existía, por consiguiente, en el grupo un concepto novedoso de la identidad continental, que sus miembros no explotaron entonces por pensar que la época imponía huir de toda forma de localismo, sin exceptuar el aspecto humano. García Márquez - flexibilidad de creador frente a quienes eran solamente analistas- supo llegar hasta el fondo de lo que era entonces una clarividente intuición.

${ }^{69}$ Gabriel García Márquez (Septimus), «Otra vez el Premio Nobel», en El Heraldo (8 de abril de 1950), p. 3. Cfr. Obra periodística, vol. 1: Textos costeños, op. cit., pp. 246-247.

70 Gabriel García Márquez (Septimus), cfr. nota 57. 
Pero todos estaban de acuerdo en que una época había terminado. Lo demuestran los primeros cuentos de Cepeda Samudio, tan experimentales, y los de García Márquez. Alfonso Fuenmayor, que tenía algunos reparos frente a $L a$ vorágine ${ }^{71}$, mientras que Germán Vargas consideraba en sus «Fichas sin revisar» que esa novela era «la mejor que (hubiera) escrito novelista alguno en Colombia», expresó el punto de vista colectivo sobre el telurismo. Por ejemplo:

Las novelas de Gallegos son ante todo documentos y también un vasto fresco sociológico. Ouizá flaquee en ellas la pericia psicológica, el escritor descriptivo, y haga excesivas concesiones a lo folletinesco, pero en esas tupidas y febriles páginas sobresale una honrada mentalidad que fraterniza con sus coterráneos ${ }^{72}$.

Y a propósito de Mario Picón-Salas:

... ha querido interpretar el americanismo sobre bases de rigor científico, sustrayéndolo del pérfido y seductor ambiente en que lo habían sumido espíritus arrebatados de metáforas, de tropicalismo exuberante ${ }^{73}$.

A esas convicciones habían llegado también por vías que no eran sólo las exclusivamente literarias que hemos mencionado hasta ahora. El grupo vivía plenamente «la hora del mundo», y dentro de los problemas del mundo insertaba los que vivía su país. En su concepto de América encontramos, es verdad, unos elementos que eran herencia de las tradicionales posturas del liberalismo, que ellos acataban a la vez por convicciones propias y por colaborar en órganos de la prensa liberal: todos eran partidarios del progreso, de la democracia y hostiles a todas las formas, también tradicionales en América Latina, de dictadura y de militarismo. Pero se situaban más allá de las actitudes del liberalismo oficial y nada tenían en común con un editorialista reaccionario como «Calibán».

En realidad, se sentían más cercanos al Partido Comunista —entonces dividido- que al Partido Liberal. Lo demuestra la forma desilusionada como vivieron la posguerra. La frecuencia con que atacaron al Generalisimo Franco en sus columnas, de 1946 a 1950, es un elemento revelador. Con ello, al parecer, no hacía sino retomar la postura oficial del liberalis-

${ }^{71}$ Alfonso Fuenmayor, 'Aire del día', "Cuatro años a bordo de mí mismo», en El Heraldo (28 de enero de 1948), p. 3.

${ }^{72}$ Alfonso Fuenmayor, 'Aire del día', «El presidente Gallegos», en El Heraldo (16 de febrero de 1948), p. 3.

${ }^{73}$ Alfonso Fuenmayor, 'Aire del día', «Mariano Picón-Salas», en El Heraldo (20 de mayo de 1948), p. 3. 
mo, pero no juzgaban solamente a Franco como un dictador militar más, sino que veían en él y en la permanencia de su poder la prolongación odiosa de los tiempos del totalitarismo nazi-fascista. Añoraban la época de unanimidad que había sido la lucha contra las potencias del Eje y se sentían defraudados y perplejos ante la nueva situación que era la guerra fría. La ilusión pacifista que había generado en América Latina la propaganda de los años de guerra seguía pareciéndoles no solamente una posibilidad, sino una necesidad, y no admitían que se dejara subsistir la mancha del régimen franquista en nombre de otra división del mundo que les parecía monstruosa ${ }^{74}$. El aún casi adolescente Cepeda Samudio fue el más vehemente en la denuncia del franquismo, pero Alfonso Fuenmayor y Germán Vargas también se refirieron mucho al problema. Y pasó más o menos lo mismo en cuanto a la guerra fría: más atrevido Cepeda, más circunspectos sus dos amigos, todos abogaron por un entendimiento internacional y sugirieron o afirmaron que el belicismo estaba de parte de Estados Unidos ${ }^{75}$, cuando la burguesía liberal adoptaba, naturalmente, y sin demora, los puntos de vista del anticomunismo. En 1948, el gran hombre para Cepeda era Henry A. Wallace, líder del efímero Partido Progresista norteamericano.

A ello se añadía la conciencia de que el mundo había entrado irremediablemente en una nueva etapa, con la explosión de la bomba de Hiroshima. El país no le prestaba mucha atención a esa realidad nueva y angustiosa: la explosión de la bomba no había merecido más despliegue en la prensa que otros hechos de la guerra mundial, y los grandes titulares, en agosto de 1945, se referían al cambio de presidente, con la renuncia de Alfonso López Pumarejo y la posesión del «designado» Alberto Lleras Camargo. El intelectual que más preocupación demostró tener por la amenaza de destrucción nuclear fue Eduardo Zalamea Borda, quien había sido el primero en hablar de su existencia, un mes antes de Hiroshima ${ }^{76}, y$ siguió hablando insistentemente de esa amenaza en los meses y años posteriores. En el grupo de Barranquilla, Cepeda Samudio fue el que más

${ }^{74}$ Notas de Alvaro Cepeda Samudio en El Nacional (5 de noviembre de 1947, 29 de enero de 1948, 14 de marzo de 1948, 29 de junio de 1948). Notas de Alfonso Fuenmayor en El Heraldo (12 de julio de 1946, 19 de julio de 1946, 17 de noviembre de 1946).

${ }^{75}$ Notas de Alvaro Cepeda Samudio en El Nacional (7 de enero de 1948, 4 de febrero de 1948, 23 de abril de 1948, 5 de mayo de 1948). Notas de Germán Vargas en El Nacional (30 de marzo de 1948, 1 de junio de 1948). Notas de Alfonso Fuenmayor en El Heraldo (9 de julio de 1946, 5 de febrero de 1948, 6 de febrero de 1948, 31 de marzo de 1948).

${ }_{76}$ Eduardo Zalamea Borda (Ulises), 'La ciudad y el mundo', «iYa existe la bomba atómica!», en El Espectador (Bogotá, 11 de julio de 1945), p. 4. 
claramente expresó la conciencia de vivir tiempos angustiosos por la existencia de la bomba atómica: lo atestiguan sus notas en El Nacional de Barranquilla, así como sus tanteos formales de escritor preocupado por penetrar y expresar la realidad más allá de sus apariencias inmediatas ${ }^{77}$. Sus compañeros del grupo, sin expresarlo, fueron conscientes del cambio que había significado en la historia de la humanidad la explosión de Hiroshima, y esa conciencia permea todas sus actitudes, incluso cuando sólo hablaban de literatura e ironizaban sobre los anacronismos colombianos ${ }^{78}$.

El grupo pretendía ir contra la corriente de la guerra fría y estaba condenado por la época a encontrarse rápidamente en un callejón sin salida. Pero ésa no era solamente una postura innocua de intelectuales, ya que la realidad mundial involucraba a Colombia, un hecho que ellos veían con más claridad que muchos otros. Significativamente, el estallido más espectacular de la "violencia» colombiana, la reacción popular ante el asesinato del líder liberal Jorge Eliécer Gaitán (9 abril 1948), se situó en los días en que estaba reunida en Bogotá la Novena Conferencia Interamericana, (la IXCIA), en la que les fue impuesta a los países latinos del continente la adopción del credo anticomunista. El grupo, que había protestado ante ciertas señales inequívocas de esa tendencia en otros países del Sur ${ }^{79}$, tanbién se dedicó a ironizar y a protestar contra la imposición ${ }^{80}$. Con efectos igualmente nulos, desde luego, ya que entre las secuelas del 9 de abril se impuso por un tiempo la censura, antes de que se agravara la «violencia» oficial y el gobierno conservador, gobierno electo, pero minoritario, se convirtiera abiertamente en dictadura para retener el poder, en noviembre de 1949. La «violencia», que los miembros del grupo, al igual que los demás liberales, condenaban en sus columnas de prensa ${ }^{81}$, arrasaba con todo.

Bajo una forma muy propia, marcada por su pasado «bipartidista»,

77 Alvaro Cepeda Samudio, «El hombre pesimista», en El Nacional (30 de octubre de 1947); «Vigencia de un cuento», en El Nacional (12 de noviembre de 1947).

${ }^{78}$ Alfonso Fuenmayor, en lo que fue la primera entrega de su columna 'Aire del día', habló de la cuestión nuclear. La nota «Otra vez Bikini», El Heraldo (8 de julio de 1946), p. 3.

${ }_{79}$ Muy especialmente Cepeda Samudio a propósito de la persecución contra Pablo Neruda ("En el margen de la ruta', "Jugando a los gringos», El Nacional, hacia el 7 de enero de 1948). Alfonso Fuenmayor escribió notas parecidas, así como Germán Vargas.

${ }^{80}$ Notas de Alvaro Cepeda Samudio (9 de marzo de 1948, 29 de marzo de 1948, 23 de abril de 1948). Notas de Alfonso Fuenmayor (18 de marzo de 1948, 6 de abril de 1948, 26 de junio de 1948).

${ }^{81}$ En particular Germán Vargas en El Nacional (notas de los días 27 de enero, 17 de febrero y 25 de junio de 1948). También Alfonso Fuenmayor (notas en El Heraldo en septiembre, octubre y noviembre de 1949). 
Colombia aclimataba en su territorio la guerra fría, y los barranquilleros -favorecidos además por la tolerancia tradicional de su ciudad y la paz que en ella siguió reinando- pudieron verlo más claramente que muchos de sus compatriotas. Su postura de intelectuales de izquierda, abocados a la impotencia y a la irrisión (allí nació entonces y se conformó ese tipo especial de humor que los colombianos, retomando una expresión venezolana, han 1lamado «mamadera de gallo»), les permitió al menos no perder de vista que el drama que vivía su país no era un hecho estrictamente nacional, sino que formaba parte de un proceso mundial y era una de las consecuencias del último conflicto planetario. También entre los miembros del grupo de Barranquilla empezaban a cobrar vida la conciencia de pertenecer a lo que aún no se llamaba el Tercer Mundo y los conceptos de la no alineación.

No se han estudiado las consecuencias que tuvieron en la vida intelectual del país la dictadura del falangismo conservador y la «violencia» -está claro que las tuvo que haber-y tampoco es posible decir qué hubiera sido, en condiciones de paz, la trayectoria del grupo después de 1950. El contraste era enorme, en todo caso, entre las esperanzas de 1945 y los bloqueos de principios de los cincuenta, y es evidente que una desilusión histórica marca los procesos del grupo. Sin embargo, se ve que sus miembros no confiaban demasiado en la posibilidad de cambiar las actitudes del país en materia de ideología y de arte a través de una prédica periodística o cultural, ya que desdeñaron las tribunas bogotanas, y que más bien prefirieron delegar esa tarea a sus artistas -Obregón, Cepeda Samudio, García Márquez - y a las obras que habían de producir en adelante. Estas recibieron un impulso del ideario cuyas huellas subsisten hoy en las colecciones de la prensa barranquillera, aunque, superada la época inicial, han llegado mucho más lejos, al haber roto sus ataduras y dejado de definirse con relación a lo provinciano y anacrónico del país de entonces. Es decir, que, sobre todo en el caso de García Márquez, el programa del grupo ha llegado a cumplirse, si no mejor de lo que entonces hubiera podido soñarse, al menos sí a cabalidad y de manera insospechada (lo cual refuerza, sin confirmarla del todo, la hipótesis de que la "violencia» no torció realmente el proceso del grupo). Una equivocación del grupo había sido, en cuestiones artísticas, su desconfianza hacia las posibilidades que aún entrañaban las realidades de la tierra y su creencia algo exclusiva en las temáticas de la ciudad. En literatura, sus conceptos generaban o esperaban a un Cortázar, pero no a un Rulfo. Curiosamente, con el tiempo, el mismo Cepeda Samudio, el más urbano de todos ellos (pensaban ellos «universal» por «urbano»), volvió a la temática de la tierra al escribir un cuento como «Hay que buscar a Regina» y una novela como 
La casa grande, pero, claro está, que con presupuestos modernos. En cuanto a las ideas de García Márquez sobre esta cuestión, resultan demasiado evidentes para que las evoquemos aquí. Sin embargo, salvo la elección de una línea urbana demasiado exclusiva en los conceptos literarios del grupo, es evidente que éste, en 1950, tenía estipulados claramente los presupuestos ideológicos y estéticos del boom y resulta como un hecho de justicia el que Cien años de soledad, obra de un autor que perteneció entonces al grupo, sea el título más caracterizado de ese fenómeno continental. El boom, de todas formas, no podía estallar en Barranquilla en 1950, sino unos años más tarde, y en varios lugares a la vez, pero a ello había contribuido el grupo por haber querido, en la Colombia de los años cuarenta, «ponerse a tono con la hora del mundo». 
